\title{
Prone Positioning Improves Pulmonary Function in Obese Patients During General Anesthesia
}

\author{
Paolo Pelosi, MD, Massimo Croci, MD, Emiliana Calappi, MD, Davide Mulazzi, MD, \\ Marco Cerisara, MD, Paola Vercesi, MD, Pierluigi Vicardi, MD, and Luciano Gattinoni, MD \\ Istituto di Anestesia e Rianimazione, Università di Milano e Servizio di Anestesia e Rianimazione, Ospedale Maggiore \\ IRCCS, Milan, Italy
}

\begin{abstract}
We investigated the effects of prone position on functional residual capacity (FRC), the mechanical properties (compliance and resistance) of the total respiratory system, lung and chest wall, and the gas exchange in 10 anesthetized and paralyzed obese (body mass index more than $30 \mathrm{~kg} / \mathrm{m}^{2}$ ) patients, undergoing elective surgery. We used the esophageal balloon technique together with rapid airway occlusions during constant inspiratory flow to partition the mechanics of the respiratory system into its pulmonary and chest wall components. FRC was measured by the helium dilution technique. Measurements were taken in the supine position and after 15-30 min of prone position maintaining the same respiratory pattern (tidal volume $12 \mathrm{~mL} / \mathrm{kg}$ ideal body weight, respiratory rate 14 breaths/ min, fraction of inspired oxygen $\left[\mathrm{FIO}_{2}\right] 0.4$ ). We found that FRC and lung compliance significantly $(P<0.01)$
\end{abstract}

increased from the supine to prone position $(0.894 \pm$ $0.327 \mathrm{~L}$ vs $1.980 \pm 0.856 \mathrm{~L}$ and $91.4 \pm 55.2 \mathrm{~mL} / \mathrm{cm} \mathrm{H}_{2} \mathrm{O}$ vs $109.6 \pm 52.4 \mathrm{~mL} / \mathrm{cm} \mathrm{H}_{2} \mathrm{O}$, respectively). On the contrary, the prone position reduced chest wall compliance (199.5 $\pm 58.7 \mathrm{~mL} / \mathrm{cm} \mathrm{H}_{2} \mathrm{O}$ vs $160.5 \pm 45.4 \mathrm{~mL} / \mathrm{cm} \mathrm{H}_{2} \mathrm{O}$, $P<0.01$ ), thus total respiratory system compliance did not change. Resistance of the total respiratory system, lung, and chest wall were not modified on turning the patients prone. The increase in FRC and lung compliance was paralleled by a significant $(P<0.01)$ improvement of $\mathrm{PaO}_{2}$ from supine to prone position (130 $\pm 31 \mathrm{vs}$ $181 \pm 28 \mathrm{~mm} \mathrm{Hg}, P<0.01$ ), while $\mathrm{PaCO}_{2}$ was unchanged. We conclude that, in anesthetized and paralyzed obese subjects, the prone position improves pulmonary function, increasing FRC, lung compliance, and oxygenation.

(Anesth Analg 1996;83:578-83)
D uring surgery, the prone position is commonly used to expose the dorsal surface of the body for specific surgical indications. In anesthetized and paralyzed normal subjects, the prone position, if correctly performed, ensures free abdominal movement, is not associated with adverse effects on respiratory mechanics, and improves lung volume and oxygenation (1). In obese patients, anesthesia and paralysis negatively affect respiratory mechanics and oxygenation more than in normal subjects (2); thus, it has been hypothesized that the prone position should be avoided whenever possible (3) and/or exercised with extreme care (4). However, this conclusion was speculative, as no data regarding respiratory function in anesthetized and paralyzed obese patients in the prone position are available.

The aim of this study was to investigate changes in lung volume, respiratory mechanics, and gas

Accepted for publication May 14, 1996.

Address correspondence and reprint requests to Paolo Pelosi, MD, Istuto di Anestesia e Rianimazione, Ospedale Maggiore IRCCS, via Francesco Sforza 35, 20122, Milan, Italy. exchange between the supine and the prone positions in a group of anesthetized and paralyzed obese subjects.

\section{Methods}

\section{Study Population}

We studied a group of 10 consecutive obese patients ( 2 males and 8 females, age $53 \pm 13 \mathrm{yr}$, height $1.60 \pm$ $0.06 \mathrm{~m}$, and weight $88.1 \pm 10.2 \mathrm{~kg}$ ) receiving general anesthesia for elective surgery requiring the prone position (i.e., removal of a herniated disk). Obesity was defined as a body mass index more than $30 \mathrm{~kg} / \mathrm{m}^{2}(5)$. The mean body mass index was $34.6 \pm$ $4.8 \mathrm{~kg} / \mathrm{m}^{2}$, ranging from 30.1 to $46.3 \mathrm{~kg} / \mathrm{m}^{2}$. All the patients were free from cardiorespiratory disease (three patients were smokers). The research was approved by our internal ethics committee, and verbal informed consent was obtained from all patients.

After receiving diazepam $10 \mathrm{mg}$ and atropine $0.5 \mathrm{mg}$, anesthesia was induced with fentanyl $0.10 \mathrm{mg}$ and propofol $2 \mathrm{mg} / \mathrm{kg}$ intravenously, and vecuronium was 
Figure 1. Tracings (top to bottom) of flow, volume, and pressure at the airway opening ( $\mathrm{Pao}$ ) and esophageal pressure (Pes), from a representative patient in the supine and the prone positions. During an end-inspiratory occlusion there was an immediate decrease in Pao from a maximum pressure value $\left(\mathrm{P}_{\max }\right)$ to a lower value (P1), followed by a slow decline to a plateau pressure (P2), that represented an end-inspiratory elastic recoil of the respiratory system (Pst,rs). In Pes no immediate decrease was notable from $\mathrm{P}_{\max }$ to P1. Plateau pressure in Pes represents the end-inpiratory elastic recoil of the chest wall $(\mathrm{Pst}, \mathrm{w}) . \mathrm{P}=$ pressure; ao = airway opening; es = esophageal; st = static; rs = respiratory system; $\mathrm{w}=$ chest wall; Insp. $=$ inspiratory.
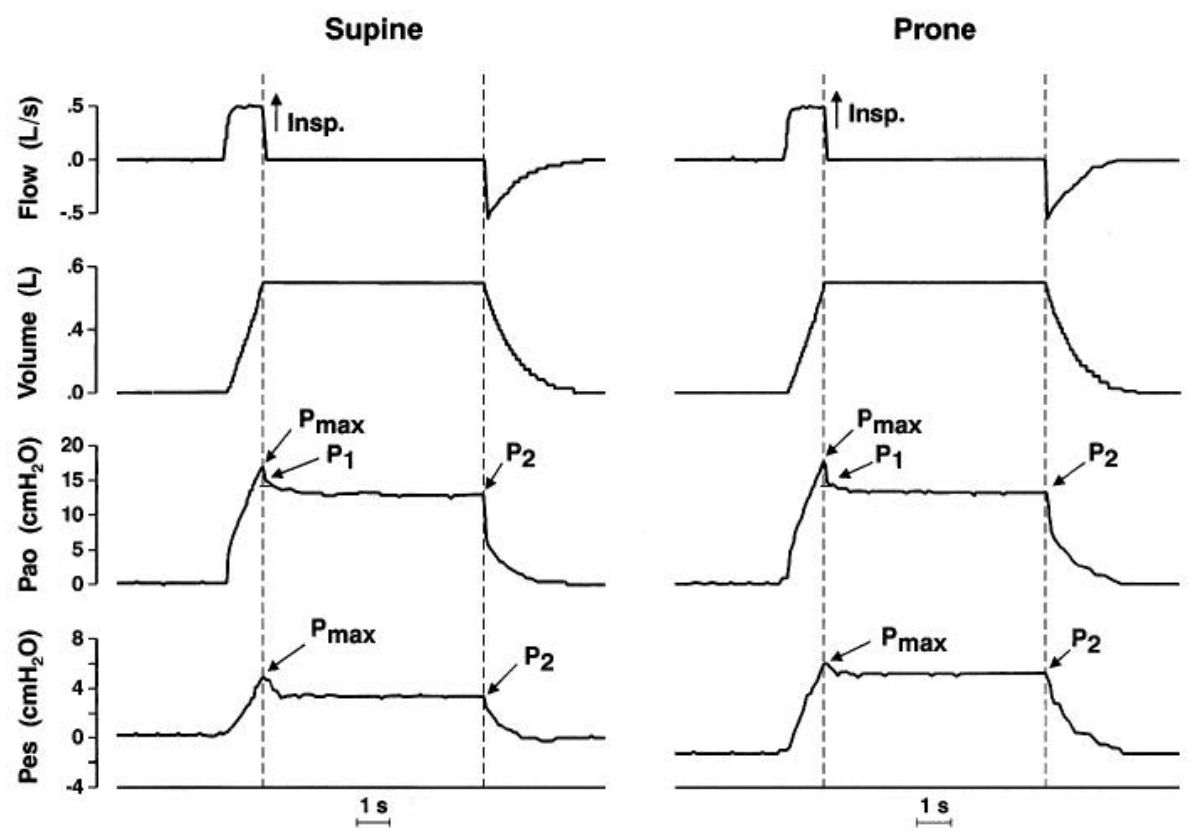

given to facilitate orotracheal intubation $(0.1 \mathrm{mg} / \mathrm{kg})$. Patients were orotracheally intubated with an Endosoft ${ }^{\circledR}$ (Hoechst, Milan, Italy) reinforced cuffed tube (7.5$8.0 \mathrm{~mm}$ inside diameter) positioned under direct laryngoscopy. Ventilation was then controlled via a mechanical ventilator (Servo $900 \mathrm{C}^{\circledR}$; Siemens Elema $\mathrm{AB}$, Berlin, Germany), using the control mode ventilation with constant inspiratory flow; the ventilator setting consisted of a fixed respiratory rate of 14 breaths/ $\mathrm{min}$, an inspiratory to expiratory time ratio of $1: 2$, a tidal volume $\left(\mathrm{V}_{\mathrm{T}}\right)$ of $12 \mathrm{~mL} / \mathrm{kg}$ ideal body weight, and an inspired oxygen fraction of 0.4 (air supplemented with oxygen). During the procedure, anesthesia was maintained with a continuous intravenous infusion of propofol (6$\left.12 \mathrm{mg} \cdot \mathrm{kg}^{-1} \cdot \mathrm{h}^{-1}\right)$ and fentanyl boluses $(0.001 \mathrm{mg} / \mathrm{kg})$, while muscle paralysis was maintained with additional aliquots of vecuronium $(0.03 \mathrm{mg} / \mathrm{kg})$.

\section{Measurement of Functional Residual Capacity (FRC)}

The FRC was measured at end-expiration using a simplified closed-circuit helium dilution method (6). Briefly, an anesthesia bag filled with $2 \mathrm{~L}$ of a known gas mixture ( $13 \%$ helium in oxygen) was connected to the airway opening at end-expiration and 10 deep manual breaths were performed. The helium concentration in the anesthesia bag was then measured with a helium analyzer (PK Morgan Ltd., Chatham, Kent, England) and FRC was computed according to the following formula:

$$
\mathrm{FRC}=\mathrm{Vi}[\mathrm{He}] \mathrm{i} /[\mathrm{He}] \mathrm{fin}-\mathrm{Vi},
$$

where $\mathrm{Vi}$ is the initial gas volume in the anesthesia bag and [He]i and [He]fin are the initial and final helium concentrations, respectively, in the anesthesia bag.

\section{Measurement of Respiratory Mechanics}

Airway pressure (Pao) was measured proximal to the endotracheal tube by means of a polyethylene catheter ( $2 \mathrm{~mm}$ inside diameter, $120 \mathrm{~cm}$ long), connected to a Bentley Trantec ${ }^{\circledR}$ pressure transducer (Bentley Lab., Irvine, $\mathrm{CA}$ ). Esophageal pressure (Pes) was measured with an esophageal balloon (CP-100; Bicore, Irvine, CA) modified to allow connection to a Bentley Trantec transducer; during measurements the balloon was inflated with 0.5$1 \mathrm{~mL}$ of air. Before induction of anesthesia, the validity of Pes was verified using the "occlusion test" method proposed by Baydur et al. (7), and the balloon fixed in that position. The occlusion test was repeated in the prone position at the end of surgery, when patients resumed spontaneous breathing.

Gas flow was recorded with a heated pneumotachograph (Fleish No. 2) connected to a Validyne MP 45-1 ${ }^{\circledR}$ differential pressure transducer (Valydine Corp., Northridge, CA). Both flow and pressure signals were recorded on a four-pen channel recorder and processed via an analog-to-digital converter by computer for storage and calculations. Volume was obtained by digital integration of the flow signal. The pressure-flow relationships of the endotracheal tubes were determined after each experiment with the use of the experimental gas mixture. These relationships were used to determine the resistive pressure decrease due to the endotracheal tubes for any given flow during tests.

As shown in Figure 1, we used the esophageal balloon technique together with transient airway occlusions during constant inspiratory flow to partition the mechanics of the respiratory system into its pulmonary and chest wall components. The end-inspiratory hold button of the Servo $900 \mathrm{C}$ was pressed for brief 
(3-4 s) airway occlusions. Occlusion was maintained until both Pao and Pes decreased from a maximum value $\left(\mathrm{P}_{\max }\right)$ to an apparent plateau (P2). After the occlusion, an immediate drop from $\mathrm{P}_{\max }$ to a lower value (P1), at flow 0, was notable in Pao but not in Pes. The plateau pressures (P2) of Pao and Pes were taken to represent the static end-inspiratory recoil pressures of the respiratory system (Pst,rs) and the chest wall (Pst,w), respectively. The static respiratory system (Cst,rs) and chest wall (Cst,w) compliances were obtained by dividing $\mathrm{V}_{\mathrm{T}}$ by the difference between Pst,rs - Pao at end-expiration and Pst,w - Pes at end-expiration, respectively. The static lung compliance (Cst,L) was obtained from Cst,rs and Cst,w according to the following equation: $1 /$ Cst,rs = $1 /$ Cst, $w+1 /$ Cst,L; thus, Cst, $\mathrm{L}=($ Cst,rs $\cdot$ Cst, $w) /$ (Cst,w - Cst,rs). An end-expiratory occlusion maneuver was always performed to exclude the possible presence of intrinsic positive end-expiratory pressure.

Maximum $\left(\mathrm{R}_{\max }, \mathrm{rs}\right)$ and minimum $\left(\mathrm{R}_{\min }, \mathrm{rs}\right)$ resistance of the respiratory system were computed from $\mathrm{Pao}$ as $\left(\mathrm{P}_{\max }{ }^{\prime}-\mathrm{P} 2\right) / \mathrm{Vi}^{\prime}$ and $\left(\mathrm{P}_{\max }{ }^{\prime}-\mathrm{P} 1\right) / \mathrm{Vi}^{\prime}$, where $\mathrm{P}_{\max }{ }^{\prime}$ represents the new $\mathrm{P}_{\max }$ value obtained correcting Pao for tube resistance (see above) and $\mathrm{Vi}^{\prime}$ is the flow immediately preceeding the occlusion. $R_{\text {min }}$ rs represents the flow resistance of airways, and $R_{\text {max }}, r s$ includes $\mathrm{R}_{\min }$, $r$ p plus the "additional" respiratory resistance caused by stress relaxation and/or time constant inequalities within the respiratory tissues. The difference between $R_{\text {max }}, r s$ and $R_{\text {min }}$ rs was termed DR,rs. Since there was no substantial decrease in Pes (i.e., P1 in the esophageal tracings was not identifiable) immediately after the occlusion, $\mathrm{R}_{\text {min }}$, rs essentially reflects airway resistance $\left(R_{\min }, L\right)$ and minimum chest wall resistance $\left(R_{\min }, w\right)$ can be considered negligible. As a consequence, maximum chest wall resistance $\left(R_{\max }, w\right)$ is entirely due to the viscoelastic properties of the chest wall tissues (i.e., $R_{\max }, w=D R, w$ ). "Additional" resistance of the lung (DR,L) was obtained as DR,rs - DR, $w$ while the sum of $R_{\min }, L+$ $D R, L$ gives the maximum lung resistance $\left(R_{\text {max }}, L\right)$. $\mathrm{DR}, \mathrm{L}$ and $\mathrm{DR}, \mathrm{w}$ (i.e., $\mathrm{R}_{\max }, \mathrm{w}$ ) were due to stress relaxation and/or time constant inequalities within the lung and chest wall, respectively (8).

\section{Study Design}

Fifteen minutes after starting the mechanical ventilation prior to surgery, analysis of blood gases, measurements of respiratory mechanics, and FRC were taken in the supine position. The patients were then positioned prone, assuring free abdominal movements with upper chest and pelvic supports, as suggested by Smith (9). All the measurements were repeated after 15-30 $\mathrm{min}$ of the prone position.

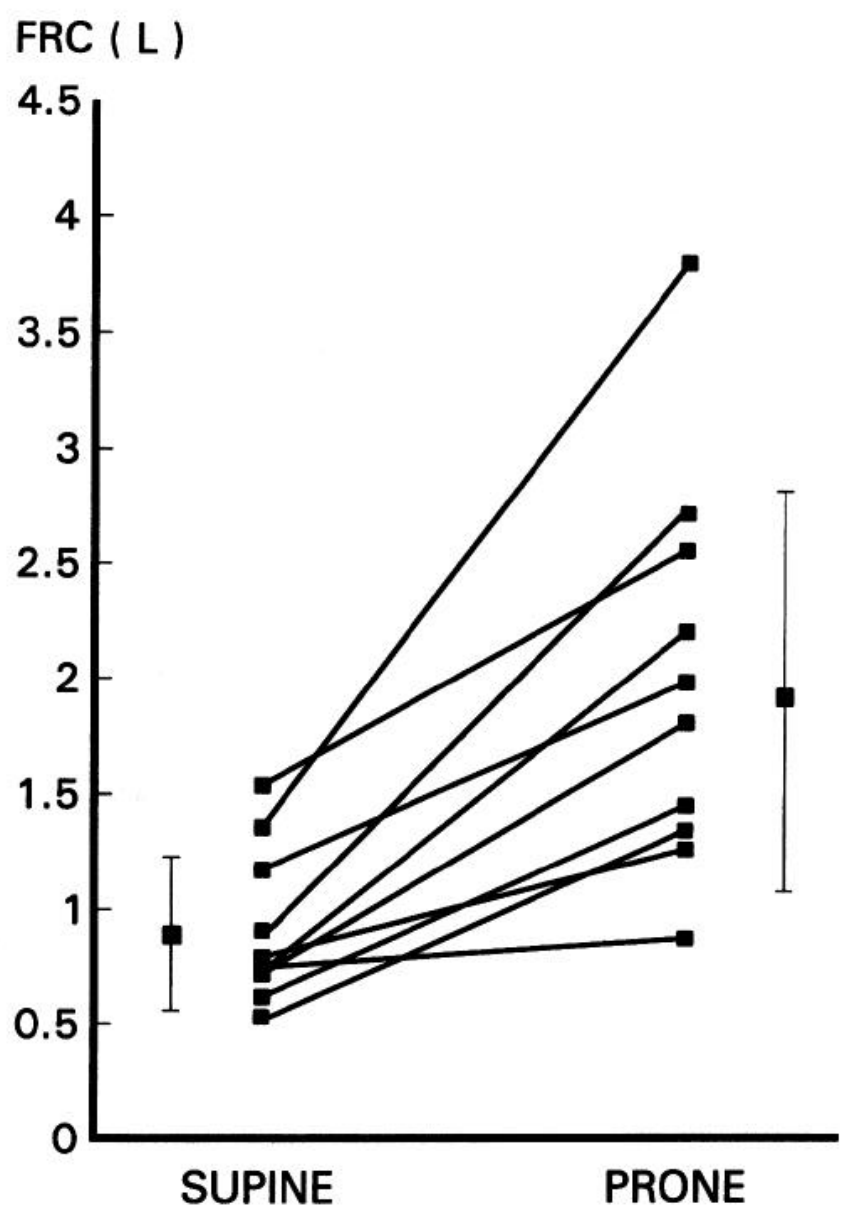

Figure 2. Individual changes in functional residual capacity (FRC) from the supine to prone position. FRC in the prone position was significantly $(P<0.01)$ more than in the supine position.

Ventilatory setting $\left(\mathrm{V}_{\mathrm{T}}\right.$ and respiratory rate) and inspired oxygen fraction were unchanged during the protocol.

\section{Statistical Analysis}

Data are expressed as mean \pm SD. All the measurements were taken in triplicate. Statistical analysis was made using a Student's paired $t$-test comparing data obtained in the supine and the prone positions. The least squares regression method was used to evaluate relationships between variables (10). $P<0.05$ was accepted as statistically significant.

\section{Results}

The delivered $\mathrm{V}_{\mathrm{T}}$ and $\mathrm{V}^{\prime} \mathrm{i}$ were similar in the supine and the prone positions $(0.760 \pm 0.090 \mathrm{~L}$ vs $0.749 \pm$ $0.110 \mathrm{~L}$ and $0.540 \pm 0.070 \mathrm{~L} / \mathrm{s}$ vs $0.530 \pm 0.070 \mathrm{~L} / \mathrm{s}$, respectively). FRC increased in all the patients from the supine to the prone position $(0.894 \pm 0.327 \mathrm{~L}$ vs $1.980 \pm 0.856 \mathrm{~L} ; P<0.01$ ) (Figure 2). From the supine to the prone position Cst,L increased (91.4 \pm 
Table 1. Total Respiratory System, Lung and Chest Wall Mechanics in Supine and Prone Positions

\begin{tabular}{|c|c|c|c|}
\hline & Supine & Prone & $P$ \\
\hline Cst,rs (mL/cm H$\left.~_{2} \mathrm{O}\right)$ & $55.4 \pm 9.6$ & $59.6 \pm 12.1$ & NS \\
\hline $\mathrm{Cst}, \mathrm{w}\left(\mathrm{mL} / \mathrm{cm} \mathrm{H}_{2} \mathrm{O}\right)$ & $199.5 \pm 58.7$ & $160.5 \pm 45.4$ & $<0.01$ \\
\hline Cst, $\mathrm{L}\left(\mathrm{mL} / \mathrm{cm} \mathrm{H}_{2} \mathrm{O}\right)$ & $91.4 \pm 55.2$ & $109.6 \pm 52.4$ & $<0.01$ \\
\hline $\mathrm{R}_{\max } \mathrm{rs}\left(\mathrm{cm} \mathrm{H}_{2} \mathrm{O} \cdot \mathrm{L}^{-1} \cdot \mathrm{s}^{-1}\right)$ & $9.6 \pm 5.2$ & $9.0 \pm 5.5$ & NS \\
\hline $\mathrm{DR}, \mathrm{rs}\left(\mathrm{cm} \mathrm{H}_{2} \mathrm{O} \cdot \mathrm{L}^{-1} \cdot \mathrm{s}^{-1}\right)$ & $4.2 \pm 1.5$ & $5.2 \pm 1.9$ & NS \\
\hline $\mathrm{R}_{\max ,} \mathrm{L}\left(\mathrm{cm} \mathrm{H} \mathrm{H}_{2} \mathrm{O} \cdot \mathrm{L}^{-1} \cdot \mathrm{s}^{-1}\right)$ & $8.2 \pm 5.6$ & $6.9 \pm 5.7$ & NS \\
\hline $\mathrm{R}_{\text {min }} \mathrm{L}\left(\mathrm{cm} \mathrm{H}_{2} \mathrm{O} \cdot \mathrm{L}^{-1} \cdot \mathrm{s}^{-1}\right)$ & $5.3 \pm 4.3$ & $3.8 \pm 3.8$ & NS \\
\hline $\mathrm{DR}, \mathrm{L}\left(\mathrm{cm} \mathrm{H}_{2} \mathrm{O} \cdot \mathrm{L}^{-1} \cdot \mathrm{s}^{-1}\right)$ & $2.8 \pm 1.6$ & $3.1 \pm 2.1$ & NS \\
\hline $\mathrm{R}_{\max }, \mathrm{W}\left(\mathrm{cm} \mathrm{H}_{2} \mathrm{O} \cdot \mathrm{L}^{-1} \cdot \mathrm{s}^{-1}\right)$ & $1.4 \pm 0.8$ & $2.1 \pm 0.9$ & NS \\
\hline
\end{tabular}

Data are expressed as mean $\pm \mathrm{sD}$.

Cst, $r \mathbf{r s}=$ respiratory system compliance; Cst, $\mathrm{w}=$ chest wall compliance; $\mathrm{Cst}, \mathrm{L}=$ lung compliance; $\mathrm{R}_{\mathrm{max}, \mathrm{rS}}=$ maximum resistance of the respiratory system;

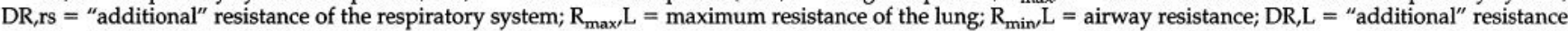
of the lung; $R_{\max }, \mathrm{w}=$ resistance of the chest wall; $\mathrm{C}=$ compliance; $\mathrm{R}=$ resistance; $s t=$ static; $r \mathrm{~s}=$ respiratory system; $\mathrm{L}=\mathrm{lung} ; \mathrm{w}=$ chest wall.

$55.2 \mathrm{~mL} / \mathrm{cm} \mathrm{H}_{2} \mathrm{O}$ vs $109.6 \pm 52.4 \mathrm{~mL} / \mathrm{cm} \mathrm{H}_{2} \mathrm{O} ; P<$ $0.01)$, while Cst, $\mathrm{w}$ decreased $(199.5 \pm 58.7 \mathrm{~mL} / \mathrm{cm}$ $\mathrm{H}_{2} \mathrm{O}$ vs $\left.160.5 \pm 45.4 \mathrm{~mL} / \mathrm{cm} \mathrm{H}_{2} \mathrm{O} ; P<0.01\right)$; as a consequence, Cst,rs was unchanged (Table 1). Respiratory, lung, and chest wall resistance, in all its components, was not significantly affected by changing position.

The improvement in FRC and Cst,L were paralleled by an increase in oxygenation in all the patients from the supine to the prone position $(130 \pm 31 \mathrm{~mm} \mathrm{Hg}$ vs $181 \pm 28 \mathrm{~mm} \mathrm{Hg}, P<0.01$ ) (Figure 3). Two patients presented only a slight increase in oxygenation, from $186 \mathrm{~mm} \mathrm{Hg}$ to $193 \mathrm{~mm} \mathrm{Hg}$ and from $150 \mathrm{~mm} \mathrm{Hg}$ to $153 \mathrm{~mm} \mathrm{Hg}$, with a marked increase in FRC, from $0.775 \mathrm{~L}$ to $1.250 \mathrm{~L}$ and from $0.700 \mathrm{~L}$ to $1.800 \mathrm{~L}$, respectively. Overall, the difference in $\mathrm{PaO}_{2}$ from the supine and the prone positions $\left(\mathrm{DPaO}_{2}\right)$ was not significantly correlated with the difference in FRC from the supine to the prone position (DFRC): $\mathrm{DPaO}_{2}(\mathrm{~mm} \mathrm{Hg})=14+$ $36 \cdot$ DFRC (L), $r=0.35 ; P>0.10$.

\section{Discussion}

In anesthetized and paralyzed obese patients, we demonstrated that the prone position, in which the abdomen moves relatively freely, increases lung volume, lung compliance, and oxygenation; thus, the prone position does not seem to have any adverse effects on pulmonary function in obese patients.

These results might reflect not only the effects of positioning but also the alterations over time, since the measurements in the prone position always followed those performed in the supine position. However, the effect of duration of mechanical ventilation and general anesthesia alone may be reasonably ruled out, since it has been consistently shown that modifications in lung volumes (11), lung and chest wall mechanics (12), and oxygenation (13) do not occur over time during general anesthesia. Moreover, although only 10 obese patients were studied, the patterns of response of all variables to position changes were the

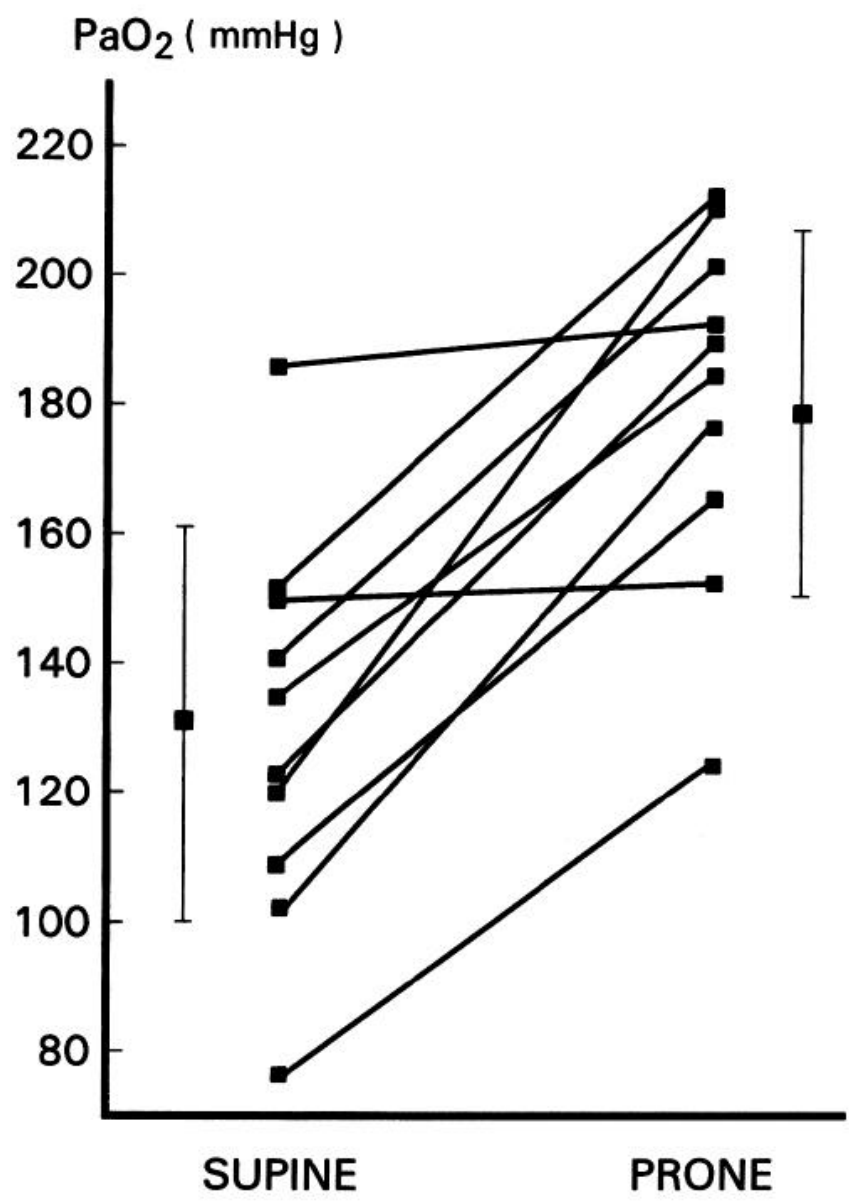

Figure 3. Individual changes in $\mathrm{PaO}_{2}$ from the supine to the prone position. $\mathrm{PaO}_{2}$ in the prone position was significantly $(P<0.01)$ increased compared to the supine position.

same in all patients. Thus, it is unlikely that the small population investigated may have affected our results.

In our anesthetized and paralyzed obese patients in the supine position, we found an average FRC value of $0.894 \pm 0.327 \mathrm{~L}$. This value is in agreement with previous observations in these kinds of patients (6) and markedly lower than what we reported in normal subjects (1). Our FRC measurements may have been 
affected by the possible presence of airway closure, which may have interfered with correct mixing of helium between the bag and the lung. If the closed airways do not open in any phase of bag ventilation, the FRC measurement will be underestimated. However, this is not a likely possibility in our study, since by using deep breaths, we reached a range of inspiratory transpulmonary pressures $\left(12-20 \mathrm{~cm} \mathrm{H}_{2} \mathrm{O}\right)$ at which the closed airways usually reopened (14).

If the closed airways open, at least in part, at each inflation and close during expiration, thus sequestrating part of the helium, the FRC measurement will be overestimated in both the supine and the prone positions. Even in normal subjects, a decreased muscular tone causes a shift of the diaphragm to a more cephalad position due to the weight of the abdominal contents (15), thus favoring the occurrence of pulmonary atelectasis and reduction in FRC (16). In obese patients, where intraabdominal pressure is likely increased from an excessive abdominal fat content, the cephalad shift of the diaphragm is probably more pronounced, leading to a greater formation of atelectasis and a decrease in FRC $(6,17)$. When patients were turned prone, FRC increased, reaching an average value of $1.980 \pm 0.856 \mathrm{~L}$.

An increase in FRC from the supine to the prone position has been previously reported also in normal anesthetized and paralyzed subjects from $1.889 \pm$ $0.624 \mathrm{~L}$ to $3.029 \pm 0.622 \mathrm{~L}$ (1). This increase in the prone position, may be explained by a reduction of the cephalad displacement of the diaphragm and/or a reopening of atelectatic segments. Since our patients were positioned to assure free abdominal movements, with upper chest and pelvic supports, the prone position probably caused an unloading of the abdominal viscera, thus reducing the pressure on the diaphragm. This, in turn, was probably the main cause of the observed increase in FRC in the prone position.

The Cst,rs in the supine position was less than previously reported in anesthetized and paralyzed normal subjects (1). The reduction in Cst,rs was mainly due to the lung component. In fact, Cst, $\mathrm{L}$ in supine obese patients was less than that previously reported in normal subjects $(1,8)$. A reduction in Cst, $L$, with approximately normal Cst, $\mathrm{w}$, in anesthetized and paralyzed obese patients has been observed also by other authors (18). The reduction in Cst, L is probably due to the severe reduction in lung volume observed in these patients, although changes in the intrinsic mechanical properties of the lung tissues or surfactant alterations cannot be excluded. By turning the patients prone, Cst,L significantly increased, while Cst, $\mathrm{w}$ decreased; thus Cst,rs did not change.

These results are different from those obtained in normal anesthetized and paralyzed subjects. In fact, Lynch et al. (19) observed a 30\%-35\% decrease in Cst,rs and an increase in peak airway pressure, when patients were positioned prone. However, they used parallel, hard rubber rolls to support the shoulders and hips, not assuring, as we did in our patients, free abdominal movements. Similar results were reported by Safar and Agusto-Escarraga (20), but in their study it was not clear how the patients were placed in the prone position. In contrast, in normal anesthetized and paralyzed subjects positioned in a way to assure free abdominal movement, as in this study, we reported no change in Cst,rs, Cst, $\mathrm{L}$, and Cst,w (1). A curvilinear volume-pressure curve of the lung may explain the different behavior of Cst, $\mathrm{L}$ in obese patients compared to normal subjects when turned prone. In fact, in obese patients, in the supine position, $\mathrm{V}_{\mathrm{T}}$ change occurred at extremely low FRC in the flatter part of the volume-pressure curve of the lung, while in the prone position, $\mathrm{V}_{\mathrm{T}}$ change occurred at higher levels of FRC in the steeper part of the curve (21). This probably indicates the occurrence of substantial alveolar recruitment of previous atelectatic regions in the prone position. On the contrary, in normal subjects, in the supine position, $\mathrm{V}_{\mathrm{T}}$ change occurred at higher FRC in the steeper part of the curve. Consequently, the increase in FRC obtained with the prone position occurred at levels of lung volume where only a small amount of alveolar recruitment, if any, and no change in the slope of volume-pressure curve of the lung were possible.

The reduction in Cst, $w$ in obese patients, may, indeed be ascribed to the positioning supports.

In this study, we also measured respiratory resistance changes partitioned into its lung and chest wall components. In the supine position both $\mathrm{R}_{\text {max }} \mathrm{L}$, $R_{\text {min }}, L$, and $D R, L$ were increased in obese patients compared to previous values reported in normal subjects at comparable volumes and inspiratory flows $(1,8)$. On the contrary, $R_{\max }, w$ was the same as normal. Comparable values of $R_{\text {max }} L$ have been reported in anesthetized and paralyzed obese subjects by other authors (2). The increase in $\mathrm{R}_{\text {min }}, \mathrm{L}$ is probably related to the lower FRC in these patients (22), while the increase in $D R, L$ probably reflects more abnormalities in stress adaptation properties of the lung and/or in dishomogeneity of ventilation (8).

On average, total lung resistance and its components, i.e., airway and "additional" lung and chest wall resistance, were not affected by the prone position. No clinically important changes in resistance from the supine to the prone position were previously reported in anesthetized and paralyzed normal subjects (1). Overall, our findings do not support the idea that the prone position significantly alters respiratory, lung, and chest wall resistance in anesthetized and paralyzed obese subjects.

The improvement in FRC and Cst,L was paralleled by an increase in oxygenation in all the subjects from $130 \pm 31 \mathrm{~mm} \mathrm{Hg}$ in the supine position to $181 \pm$ 
$28 \mathrm{~mm} \mathrm{Hg}$ in the prone position. We reported similar improvement in oxygenation in the prone position in normal anesthetized and paralyzed subjects (1). The mechanisms by which the prone position during anesthesia and paralysis improves oxygenation have not been yet elucidated. Proposed explanations include a prone position-induced 1) increase in FRC, 2) change in regional diaphragm movements and consequent changes in regional ventilation, and 3) redistribution of perfusion along a gravitational gradient toward less atelectatic lung regions (23).

As in normal subjects, we did not find any significant correlation between changes in FRC and oxygenation. Consequently, although on average FRC increased in the prone position, the increase in FRC alone may not fully explain the improvement in oxygenation.

Oxygenation depends on matching of regional ventilation and regional perfusion. By turning the patient prone, regional ventilation increases in the more expanded, nondependent regions. This has been confirmed by a recent computed tomographic study showing a predominant motion of nondependent diaphragm regions during mechanical ventilation in the prone position (24). On the other hand, at least in animal experiments, regional perfusion in the prone position does not change or becomes more uniform along the vertical gradient when compared to the supine position (25). Thus the regional ventilation/ perfusion matching improves, and may explain the beneficial effects of the prone position on oxygenation.

In conclusion, we found that anesthetized and paralyzed obese patients in the supine position have marked reductions in lung volume, alterations in lung mechanics (low compliance and high resistance), and moderate hypoxemia. We demonstrated that the prone position, if correctly performed assuring free abdominal movement, is safe in obese patients, since it improves pulmonary function.

\section{References}

1. Pelosi P, Croci M, Calappi E, et al. The prone position during general anesthesia minimally affects respiratory mechanics while improving functional residual capacity and increasing oxygen tension. Anesth Analg 1995;80:955-60.

2. Hedenstierna $G$, Santesson. J. Breathing mechanics, dead space and gas-exchange in extremely obese, breathing spontaneously and during anesthesia with intermittent positive pressure ventilation. Acta Anacsthesiol Scand 1976;20:248-54.

3. Fisher A, Waterhouse TD, Adams AP. Obesity: its relation to anaesthesia. Anaesthesia 1975;30:633-47.
4. Vaughan RW, Vaughan MS. Unusual patients: pathologic obesity. In Martin JT, ed. Positioning in anesthesia and surgery. Philadelphia: WB Saunders, 1987:281-90.

5. Bray GA. Pathophysiology of obesity. Am J Clin Nutr 1992;55: 488S-494S.

6. Damia G, Mascheroni D, Croci M, Tarenzi L. Perioperative changes in functional residual capacily in morbidly obese patients. Br J Anaesth 1988;60:574-8.

7. Baydur A, Behrakis PK, Zin WA, et al. A simple method for assessing the validity of esophageal balloon technique. Am Rev Respir Dis 1983;126:788-91.

8. D'Angelo E, Robatto FM, Calderini E, et al. Pulmonary and chest wall mechanics in anesthetized-paralyzed humans. J Appl Physiol 1991;70:2602-10.

9. Smith RH. One solution to the problem of the prone position for surgical procedures. Anesth Analg 1974;53:211-24.

10. Armitage P. Statistical methods in medical research. Oxford, UK: Blackwell, 1971.

11. Hewlett AM, Hulands GH, Nunn JF, Milledge JS. Functional residual capacity during anesthesia. III. Artificial ventilation. Br J Anaesth 1974;46:495-503.

12. Baydur A, Sassoon CSH, Stiles CM. Partitioning of respiratory mechanics in young adults: effects of duration of anesthesia. Am Rev Respir Dis 1987;135:165-72.

13. Panday J, Nunn JF. Failure to demonstrate progressive falls of arterial PO2 during anesthesia. Anesthesia 1968;23:38-46.

14. Glaister DH, Schroter RC, Sudlow MF, Milic-Emili J. Transpulmonary pressure gradient and ventilation distribution in excised lungs. Respir Physiol 1973;17:347-64.

15. Froese $\mathrm{AB}$, Bryan $\mathrm{CH}$. Effects of anesthesia and paralysis on diaphragmatic mechanics in man. Anesthesiology 1974;41: 242-55.

16. Brismar B, Hedenstierna G, Lundquist H, et al. Pulmonary densities during anesthesia: a proposal of atelectasis. Anesthesiology 1985;62:422-8.

17. Strandberg A, Tokics L, Brismar B, et al. Constitutional factors promoting development of atelectasis during anesthesia. Acta Anaesthesiol Scand 1987;31:21-4.

18. Van Lith P, Johnson FN, Sharp JT. Respiratory elastances in relaxed and paralyzed states in normal and abnormal men. J Appl Physiol 1967;23:475-86.

19. Lynch S, Brand L, Levy A. Changes in lung-thorax compliance during orthopedic surgery. Anesthesiology 1959;20:278-82.

20. Safar P, Agusto-Escarraga L. Compliance in apneic anesthetized adults. Anesthesiology 1959;20:283-9.

21. Rheder K, Marsh HM. Respiratory mechanics during anesthesia and mechanical ventilation. In: Macklem PT, Mead J, eds. Handbook of physiology. Vol 3. Section 3: The respiratory system. Mechanics of breathing. Bethesda, MD: American Physiological Society, 1986:737-52.

22. Zerah F, Harf A, Perlemuter L, et al. Effects of obesity on respiratory resistance. Chest 1993;103:1470-6.

23. Lamm WJE, Graham MM, Albert RK. Mechanism by which the prone position improves oxygenation in acute lung injury. Am J Respir Crit Care Med 1994;150:184-93.

24. Krayer S, Rehder K, Vettermann J, et al. Position and motion of the human diaphragm during anesthesia-paralysis. Anesthesiology 1989;70:891-8.

25. Glenny RW, Lamm WJE, Albert RK, Robertson HT. Gravity is a minor determinant of pulmonary blood flow distribution. J Appl Physiol 1991;71:620-9. 